\title{
Common physiological processes control mercury reduction during
}

\section{photosynthesis and fermentation}

4 Running title: Isotopes unify bacterial controls on $\mathrm{Hg}$ reduction

6 Daniel S. Grégoire ${ }^{\mathrm{a} * \#}$, Sarah E. Janssen ${ }^{\mathrm{b}}$, Noémie C. Lavoie ${ }^{\mathrm{a}}$, Michael T. Tate ${ }^{\mathrm{b}}$, \& Alexandre J.

7 Poulain $^{\text {a }}$

8 a - Biology Department, University of Ottawa, 30 Marie Curie, Ottawa, ON, K1N 6N5, Canada.

9 b - Upper Midwest Water Science Center, USGS, Middleton, Wisconsin 53562, USA.

10

11 \# Corresponding author: Dr. Daniel S. Grégoire, daniel.gregoire@uwaterloo.ca

12 * Current affiliation: Biology Department, University of Waterloo, 200 University Ave W,

13 Waterloo, ON, N2L 3G1

14

15 Word count for abstract: 248

16

17 Word count for text (excluding abstract and importance sections): 4968

18 


\section{ABSTRACT}

22 Mercury $(\mathrm{Hg})$ is a global pollutant and potent neurotoxin that bioaccumulates in food webs as

23 monomethylmercury (MeHg). The production of MeHg is driven by anaerobic and $\mathrm{Hg}$ redox

24 cycling pathways such as $\mathrm{Hg}$ reduction, which control the availability of $\mathrm{Hg}$ to methylators.

25 Anaerobes play an important role in $\mathrm{Hg}$ reduction in methylation hotspots, yet their contributions

26 remain underappreciated due to how challenging these pathways are to study in the absence of

27 dedicated genetic targets and low levels of $\mathrm{Hg}^{0}$ in anoxic environments. In this study we used $\mathrm{Hg}$

28 stable isotope fractionation to explore $\mathrm{Hg}$ reduction during anoxygenic photosynthesis and

29 fermentation in the model anaerobe Heliobacterium modesticaldum Ice1. We show that cells

30 preferentially reduce lighter $\mathrm{Hg}$ isotopes in both metabolisms leading to mass-dependent

31 fractionation, but mass-independent fractionation commonly induced by UV-visible light is

32 absent. We show that isotope fractionation is affected by the interplay between pathways

33 controlling Hg recruitment, accessibility, and availability alongside metabolic redox reactions.

34 The combined contributions of these processes lead to isotopic enrichment during anoxygenic

35 photosynthesis that is in between the values reported for anaerobic respiratory microbial $\mathrm{Hg}$

36 reduction and abiotic photoreduction. Isotope enrichment during fermentation is closer to what

37 has been observed in aerobic bacteria that reduce $\mathrm{Hg}$ through dedicated detoxification pathways.

38 These results demonstrate that common controls exist at the atomic level for Hg reduction during

39 photosynthesis and fermentation in H. modesticaldum. Our work suggests that similar controls

40 likely underpin diverse microbe-mediated $\mathrm{Hg}$ transformations that affect $\mathrm{Hg}$ 's fate in oxic and

41 anoxic habitats. 


\section{IMPORTANCE}

45 Anaerobic and photosynthetic bacteria that reduce mercury affect mercury delivery to microbes

46 in methylation sites that drive bioaccumulation in food webs. Anaerobic mercury reduction

47 pathways remain underappreciated in the current view of the global mercury cycle because they

48 are challenging to study, bearing no dedicated genetic targets to establish physiological

49 mechanisms. In this study we used stable isotopes to show that common physiological processes

50 control mercury reduction during photosynthesis and fermentation in the model anaerobe

51 Heliobacterium modesticaldum Ice1. The sensitivity of isotope analyses highlighted the subtle

52 contribution of mercury uptake towards the isotope signature associated with anaerobic mercury

53 reduction. When considered alongside the isotope signatures associated with microbial pathways

54 for which genetic determinants have been identified, our findings underscore the narrow range of

55 isotope enrichment that is characteristic of microbial mercury transformations. This suggests that

56 there exist common atomic-level controls for biological mercury transformations across a broad

57 range of geochemical conditions. 


\section{INTRODUCTION}

Mercury $(\mathrm{Hg})$ is a global pollutant and potent neurotoxin that bioaccumulates in aquatic and

61 terrestrial food webs as monomethylmercury $(\mathrm{MeHg})(1)$. Anaerobic microbes with the $h g c A B$

62 gene cluster, which encodes for the metabolic machinery responsible for $\mathrm{Hg}$ methylation (2),

63 contribute to MeHg production in habitats such as aquatic sediments, water columns, and

64 flooded soils (3-6). Hg methylation is thought to occur intracellularly and as such, it is ultimately

65 controlled by the bioavailability of $\mathrm{Hg}$ to methylators in anoxic habitats (7).

Hg redox cycling plays a key role in determining the inorganic $\mathrm{Hg}$ substrates available to methylators. Its role is two-fold: anaerobic $\mathrm{Hg}^{0}$ oxidation can supply dissolved $\mathrm{Hg}^{\mathrm{II}}$ required to generate $\mathrm{MeHg}$ and evasion of $\mathrm{Hg}^{0}$ due to reduction can limit $\mathrm{MeHg}$ production by removing inorganic $\mathrm{Hg}$ substrates. Although it is well established that abiotic photochemical $\mathrm{Hg}$ reduction dominates $\mathrm{Hg}$ redox cycling in oxic surface systems where light is present $(8-16), \mathrm{Hg}$ reduction pathways in anoxic zones where $\mathrm{Hg}$ methylation occurs have mostly been characterized under laboratory conditions and remain challenging to assess in the field.

Anoxic $\mathrm{Hg}$ reduction can occur via abiotic redox reactions with dissolved organic carbon

74 (17) and magnetite $(18,19)$, but also through biotic pathways mediated by chemotrophic and

75 phototrophic microorganisms (20-24). Unlike many aerobes that reduce $\mathrm{Hg}$ using dedicated enzymatic machinery encoded by the mer operon $(25,26), \mathrm{Hg}$ reduction in anaerobes occurs

77 through cometabolic pathways tied to anaerobic respiration, fermentation, and anoxygenic

78 photosynthesis (20-24). In contrast to mer-mediated Hg reduction and demethylation, dedicated

79 genetic determinants have yet to be identified for anaerobic Hg reduction, making these

80 pathways challenging to study from a mechanistic standpoint. Furthermore, while some studies

81 have shown that $\mathrm{Hg}^{0}$ can significantly contribute to $\mathrm{Hg}$ speciation in anoxic habitats $(27,28)$, it is 
82 possible that low levels of $\mathrm{Hg}^{0}$ are maintained by an active cycle of reduction and oxidation (29).

83 In the absence of genetic targets and measurable $\mathrm{Hg}^{0}$ accumulation, the contributions of

84 anaerobic $\mathrm{Hg}^{0}$ production to global $\mathrm{Hg}$ cycling remain cryptic and difficult to assess.

85 The use of stable $\mathrm{Hg}$ isotope fractionation is a powerful tool for providing

86 biogeochemical proxies for different abiotic and biotic $\mathrm{Hg}$ transformations (30, 31). All abiotic

87 and biotic $\mathrm{Hg}$ transformation pathways studied to date demonstrate kinetic mass dependent

88 fractionation (MDF) in which the product pool becomes isotopically lighter (enrichment of light

89 isotopes) as the reaction proceeds (32). Some pathways, such as abiotic photochemical reduction

90 and demethylation, also demonstrate mass independent fractionation (MIF), which is defined as

91 the fractionation that occurs outside of the predicted MDF pattern (30). MIF is most commonly

92 observed due to the magnetic isotope effect for odd- $\mathrm{Hg}$ isotopes ${ }^{199} \mathrm{Hg}$ and ${ }^{201} \mathrm{Hg}$ in the presence

93 of sunlight (33) and the extent to which MIF occurs is controlled in part by water chemistry and

94 the presence of photosynthetic organisms (39).

The combination of MDF and MIF tracers, and the rate of isotopic enrichment, referred

96 to as fractionation factor, can be used to outline the underlying components of different $\mathrm{Hg}$

97 microbe-mediated $\mathrm{Hg}$ transformation pathways. Over the last decade, $\mathrm{Hg}$ isotope fractionation

98 has been studied in microbes capable of mer-mediated reduction (34) and $\mathrm{MeHg}$ demethylation

99 (35); anaerobic non-mer-mediated $\mathrm{Hg}$ reduction $(36,37)$; $\mathrm{Hg}$ methylation (37-40); and oxygenic

100 phototrophic $\mathrm{MeHg}$ degradation and $\mathrm{Hg}$ reduction (41). These studies have yielded valuable

101 insights and mechanistic details that explain how microbes interact with $\mathrm{Hg}$ at the atomic level

102 making them a promising option for studying mechanisms for anaerobic $\mathrm{Hg}$ reduction. 
Our objective in this study was to characterize $\mathrm{Hg}$ isotope fractionation patterns during anoxygenic phototrophic and fermentative $\mathrm{Hg}^{\mathrm{II}}$ reduction, for which there exists no data. By

106 providing the first isotopic characterization of these pathways we aim to better understand the

107 underlying physiological pathways involved in anaerobic $\mathrm{Hg}$ reduction and their role in

108 controlling $\mathrm{Hg}$ availability to methylators in anoxic habitats. In this work, we test whether $\mathrm{Hg}$

109 reduction by the model anaerobe Heliobacterium modesticaldum Ice1 during anoxygenic

110 photosynthesis and fermentation leads to distinct isotope enrichment signatures, which would

111 suggest the different metabolic $\mathrm{Hg}$ reduction pathways are controlled by separate processes. We

112 also compare our results to previously published isotope signatures for biotic and abiotic $\mathrm{Hg}$

113 transformations to critically evaluate whether common controls exist for microbe-mediated $\mathrm{Hg}$

114 transformations. Finally, we discuss whether current analytical capacity for isotope fractionation

115 can be used to track the contributions of such pathways in the environment.

\section{METHODS}

\section{Cell growth conditions and bioreactor setup}

119 All experiments with live cells employed the strain Heliobacterium modesticaldum Ice1 grown

120 in PYE medium. Phototrophic cultures were grown at a constant visible light intensity of 80

$121 \mu \mathrm{mol}$ photon $\mathrm{m}^{-2} \mathrm{~s}^{-1}$ with a peak irradiance in the near-red to red spectrum $(600 \mathrm{~nm}$ to $700 \mathrm{~nm})$ at

$12250^{\circ} \mathrm{C}$ whereas chemotrophic cultures were grown in the dark at $50^{\circ} \mathrm{C}$ in line with our previous

123 work (23). H. modesticaldum Ice1 was obtained from the DSMZ culture collection (catalogue

124 number DSM-792). The bioreactor methodology employed in these experiments was similar to

125 the one used in previous work (23) with the following modifications: the bioreactor was

126 periodically supplied with sterile nitrogen gas that passed through an activated carbon filter and a 
$1270.2 \mu \mathrm{m}$ pore size air filter at a flow rate of $0.25 \mathrm{~L} \mathrm{~min}^{-1}$ and two gold traps were connected in

128 series at the reactor outlet to capture $\mathrm{Hg}^{0}$ (Fig S1).

129 The bioreactor was kept in an incubator set to $50^{\circ} \mathrm{C}$. Phototrophic experiments were

130 performed using a $60 \mathrm{~W}$ incandescent light bulb with a visible light intensity being maintained at

$13120 \mu \mathrm{mol}$ photon $\mathrm{m}^{-2} \mathrm{~s}^{-1}$ and mirroring the irradiance of growth conditions. Chemotrophic

132 experiments were performed in the dark. Background $\mathrm{Hg}^{0}$ was purged and removed from

133 reactors prior to phototrophically or chemotrophically-grown $H$. modesticaldum cells being

134 added as a $10 \%(\mathrm{v} / \mathrm{v})$ inoculum wherein an additional subsample was withdrawn to verify initial

135 cell density via O.D. $600 \mathrm{~nm}$. For sterile treatments, no cells were added to the bioreactor and the

136 volume of growth medium was adjusted to ensure experiments were carried out at a working

137 volume of $500 \mathrm{~mL}$. In all experiments, NIST 3133, a standard with known Hg isotopic

138 composition, was added to the bioreactor to approximately10 $\mathrm{nM} \mathrm{Hg}$ final concentration.

139 Additional details on bioreactor setup are provided in Supporting Methods.

$141 \quad \mathbf{H g}^{0}$ measurements

142 The bioreactor was bubbled periodically rather than continuously in contrast to previous work

143 because continuous bubbling led to fouling of gold traps and poor total $\mathrm{Hg}(\mathrm{THg})$ and isotope

144 recoveries. Subsamples were collected at designated timepoints by connecting dual gold traps to

145 the reactor, purging the reactor for $30 \mathrm{~min}$ to collect $\mathrm{Hg}^{0}$. In the final $5 \mathrm{mins}$ the reactor liquid

146 was sampled for $\mathrm{Hg}^{\mathrm{II}}$ concentration, isotopic composition, and cell growth after which gas flow

147 was stopped. All gold traps were capped to prevent $\mathrm{Hg}^{0}$ loss and aqueous samples were

148 conserved with $1 \%(\mathrm{v} / \mathrm{v})$ trace element grade $\mathrm{HCl}$ at $4^{\circ} \mathrm{C}$ in the dark. Reactor washes were

149 performed following previously established protocols (23). 


\section{Total Hg analyses and sample preparation for stable isotope measurements}

151 All samples for aqueous $\mathrm{Hg}$ analyses were oxidized with $10 \%(\mathrm{v} / \mathrm{v})$ bromine chloride $(\mathrm{BrCl})$ in

152 line with previous work (40) and THg concentrations were determined by stannous chloride

153 reduction coupled to cold vapor atomic fluorescence spectrometry (42). During THg analysis,

154 duplicates and matrix standard spikes were analyzed every 10 samples; analyses showed less

155 than $10 \%$ relative percent difference between duplicates and spike recoveries of $90-110 \%$. The 156 detection limit was $0.2 \mathrm{pM}$.

157 Total Hg mass balances were calculated in line with previous work $(23,24)$ with

158 corrections to account for the mass of $\mathrm{Hg}$ removed for each subsample. For $\mathrm{Hg}^{0}$ collected onto

159 gold traps, a thermal desorption system was used to liberate $\mathrm{Hg}^{0}$ over a $40 \mathrm{~min}$ desorption cycle

160 which was then captured in $40 \% \mathrm{HNO}_{3}: \mathrm{BrCl}(3: 1)$ oxidizing solution. An aliquot of the trapping

161 solution was subsequently analyzed for $\mathrm{THg}$ concentration following the protocol established in

162 previous work (43). Desorption efficiency during pre-concentration was tested by trapping a

163 NIST 3133 standard with each batch of samples, and recoveries for standard trapping were

$164101.27 \pm 4.26(n=15)$. THg recoveries from bioreactor experiments were $94.90 \pm 9.50 \%(n=7)$

165 (Fig S2).

\section{Hg stable isotope analyses}

168 Using the previously determined THg concentration, an aliquot of the trapping solution was

169 diluted with ultra-high purity water to an acid content $<10 \% \mathrm{H}^{+}$and a $\mathrm{THg}$ concentration of 3.75

170 to $5.00 \mathrm{nM}$ (44). A Neptune Plus multicollector-inductively coupled plasma mass spectrometer

171 (MC-ICP-MS) was used for $\mathrm{Hg}$ stable isotope ratio measurements. A concentration and matrix-

172 matched NIST $3133 \mathrm{Hg}$ was used for standard sample bracketing (45). To achieve detection at 
173 low Hg concentrations, Hg was reduced with stannous chloride in-line then introduced

174 continuously into a custom designed gas liquid separator along with a thallium standard (NIST

$175 \mathrm{SRM} 997,195 \mathrm{nM}$ in 3\% $\mathrm{HCl})$ for mass bias correction $(44,46)$. MC-ICP-MS instrument

176 conditions and analytical expectations derived from previously published work and quality

177 control metrics for $\mathrm{Hg}$ stable isotope analysis are provided in Supporting Methods, Table S1

178 and Table S2.

179

180 Isotope calculations

181 Delta calculations followed the conventions set forth by others (45). This convention calls for

182 mass dependent fractionation (MDF) to be expressed in terms of $\delta^{\mathrm{xxx}} \mathrm{Hg}$ where graphically

$183 \delta^{202} \mathrm{Hg}$ is used to signify MDF. $\delta^{\mathrm{xx}} \mathrm{Hg}$ is calculated as:

184

$$
\delta^{\mathrm{xxx}} \mathrm{Hg}(\%)=\left[\left({ }^{\mathrm{xxx}} \mathrm{Hg} /{ }^{198} \mathrm{Hg}_{\text {sample }}\right) /\left({ }^{\mathrm{xxx}} \mathrm{Hg} /{ }^{198} \mathrm{Hg}_{\text {NIST-3133 }}\right)-1\right] \times 1000 . \quad(\mathbf{E q ~ 1})
$$

$185 \mathrm{XXX}$ is used to signify the isotope of interest. Hg also undergoes MIF of both even and odd

186 isotopes. Here, odd-MIF is described by $\Delta^{199} \mathrm{Hg}$ and even-MIF by $\Delta^{200} \mathrm{Hg}$. MIF is calculated as:

$$
\Delta^{\mathrm{xxx}} \mathrm{Hg} \approx \delta^{\mathrm{xxx}} \mathrm{Hg}-\left(\delta^{202} \mathrm{Hg} * \beta\right) .(\mathbf{E q} 2)
$$

$188 \beta$ denotes the mass dependent scaling constant, which is determined by the laws of mass

189 dependence (45). Isotope enrichment effects based on the ratio of products to reactants (i.e. $\varepsilon_{\mathrm{p} / \mathrm{r}}$,

190 herein referred to as $\varepsilon_{\mathrm{AP}}$ for anoxygenic phototrophic reduction and $\varepsilon_{\mathrm{FM}}$ for fermentative

191 reduction) were calculated using Rayleigh fractionation models to account for the $\mathrm{Hg}^{0}$ that was

192 removed following methods from previous work on microbial $\mathrm{Hg}$ reduction (34). 
194 This method involved fitting a linear regression (shown in Fig S3, Fig S4, and Table S3) based 195 on the change in relative isotope ratios, $\ln \left(\mathrm{R} / \mathrm{R}_{0}\right)$, as a function of $\ln \left(\mathrm{f}_{\mathrm{r}}\right)$ where:

$$
\mathrm{R}=\left(\delta^{202} \mathrm{Hg} / 1000\right)+1 \text { for } \mathrm{Hg}^{\mathrm{II}} \text { (reactant) or } \mathrm{Hg}^{0} \text { (product) at a given time point and }
$$

$198 \mathrm{f}_{\mathrm{r}}=\mathrm{Hg}^{\mathrm{II}}$ in the reactor at a given time $/ \mathrm{Hg}^{\mathrm{II}}$ in the reactor at the start of the experiment $(\mathbf{E q} \mathbf{4})$;

199 and the slope of the linear regression, which is equivalent to $\varepsilon_{\mathrm{AP}}$ or $\varepsilon_{\mathrm{FM}}$ :

$$
\varepsilon=\ln \left(\mathrm{R} / \mathrm{R}_{0}\right) / \ln \left(\mathrm{f}_{\mathrm{r}}\right)(\mathbf{E q} \mathbf{5})
$$

201 We chose to use the total $\mathrm{Hg}$ analyses from the bioreactor to establish $\mathrm{f}_{\mathrm{r}}$ as this is a true

202 representation of the instantaneous isotope fractionation rather than a time integrated sample

203 following the methods outlined in previous work (34). Note that in our slope calculations we do

204 not have data for ${ }^{202} \mathrm{Hg}^{0}$ when $\mathrm{f}_{\mathrm{r}}=1$ (the $0 \mathrm{~h}$ sampling point) because no isotope fractionation was

205 taking place prior to the start of $\mathrm{Hg}$ reduction (Table S2 and Table S3). Additional calculations

206 for isotope mass balances were carried out to test for deviation from the Rayleigh fraction model

207 and can be found in Table S4. $\varepsilon$ values for MDF were compiled from previous studies on pure

208 microbial cultures and abiotic $\mathrm{Hg}$ transformations for comparison purposes. Currently, there is

209 no standard guideline for how to calculate $\varepsilon$ and studies vary widely in how they present isotope

210 enrichment data and their associated variability. We have provided details on how we normalized

$211 \varepsilon$ values from different studies in Table S5. In this work we only compared enrichment factors

212 from studies that used MC-ICP-MS techniques that were in line with our analyses, however we

213 have included all of the enrichment factors for microbe-driven $\mathrm{Hg}$ transformations published to

\section{4 date in Table S5.}




\section{RESULTS AND DISCUSSION}

\section{$218 \mathbf{H g}^{\mathbf{0}}$ production during anoxygenic photosynthesis and fermentation}

219 In our experiments $\mathrm{Hg}^{0}$ production relied on the presence of live cells for both chemotrophic and

220 phototrophic growth conditions. Cumulative $\mathrm{Hg}^{0}$ production was an order of magnitude higher

221 for live cell treatments compared to abiotic controls ( $>0.60 \mathrm{vs}<0.05 \mathrm{nmol})$ (Fig 1).

222 Chemotrophic cells produced double the amount of $\mathrm{Hg}^{0}$ compared to phototrophic cells (1.33 to

2231.64 nmol vs 0.60 to $0.81 \mathrm{nmol}$, respectively) despite having been supplied with slightly less $\mathrm{Hg}^{\mathrm{II}}$

224 (Fig 1B, E). In relative terms, phototrophic cells reduced 12 to $15 \%$ of the initial $\mathrm{Hg}^{\mathrm{II}}$ supplied

225 whereas chemotrophic cells reduced 31 to $40 \%$ (Fig S2).

Relative $\mathrm{Hg}^{0}$ production in these experiments was lower, yet consistent with our previous

227 work, which showed chemotrophically-grown cells reduced $15 \%$ more $\mathrm{Hg}^{\mathrm{II}}$ than

228 phototrophically-grown cells, reducing between 60 to $75 \%$ of the initial $\mathrm{Hg}^{\mathrm{II}}$ supplied (23). The

229 relative amount of $\mathrm{Hg}^{0}$ production did not increase with higher $\mathrm{Hg}^{\mathrm{II}}$ exposure $(10 \mathrm{nM})$ versus

230 previous experiments $(250 \mathrm{pM})(23)$. It is unlikely that the lower reduction rate observed in the

231 experiments presented here was due to the toxicity of $10 \mathrm{nM} \mathrm{Hg}$ supplied, given that $H$.

232 modesticaldum grows well under the same conditions at 50 times higher $\mathrm{Hg}$ concentrations (23).

233 Instead, we suspect that the lack of constant bubbling of the reactor may be responsible for the

234 observed results. It is possible that the accumulation of $\mathrm{CO}_{2}$ in the bioreactor following organic

235 carbon oxidation may compete with $\mathrm{Hg}^{\mathrm{II}}$ as an electron sink, decreasing the amount of $\mathrm{Hg}^{0}$

236 produced. Inorganic carbon is required for anaplerotic reactions that fulfill the biosynthetic needs

237 of $H$. modesticaldum and $\mathrm{CO}_{2}$ could have competed with $\mathrm{Hg}^{\mathrm{II}}$ for reducing power, as previously

238 shown (47). These results could also be due to $\mathrm{Hg}^{0}$ oxidation allowed by the increased residence 

anaerobes $(48,49)$.
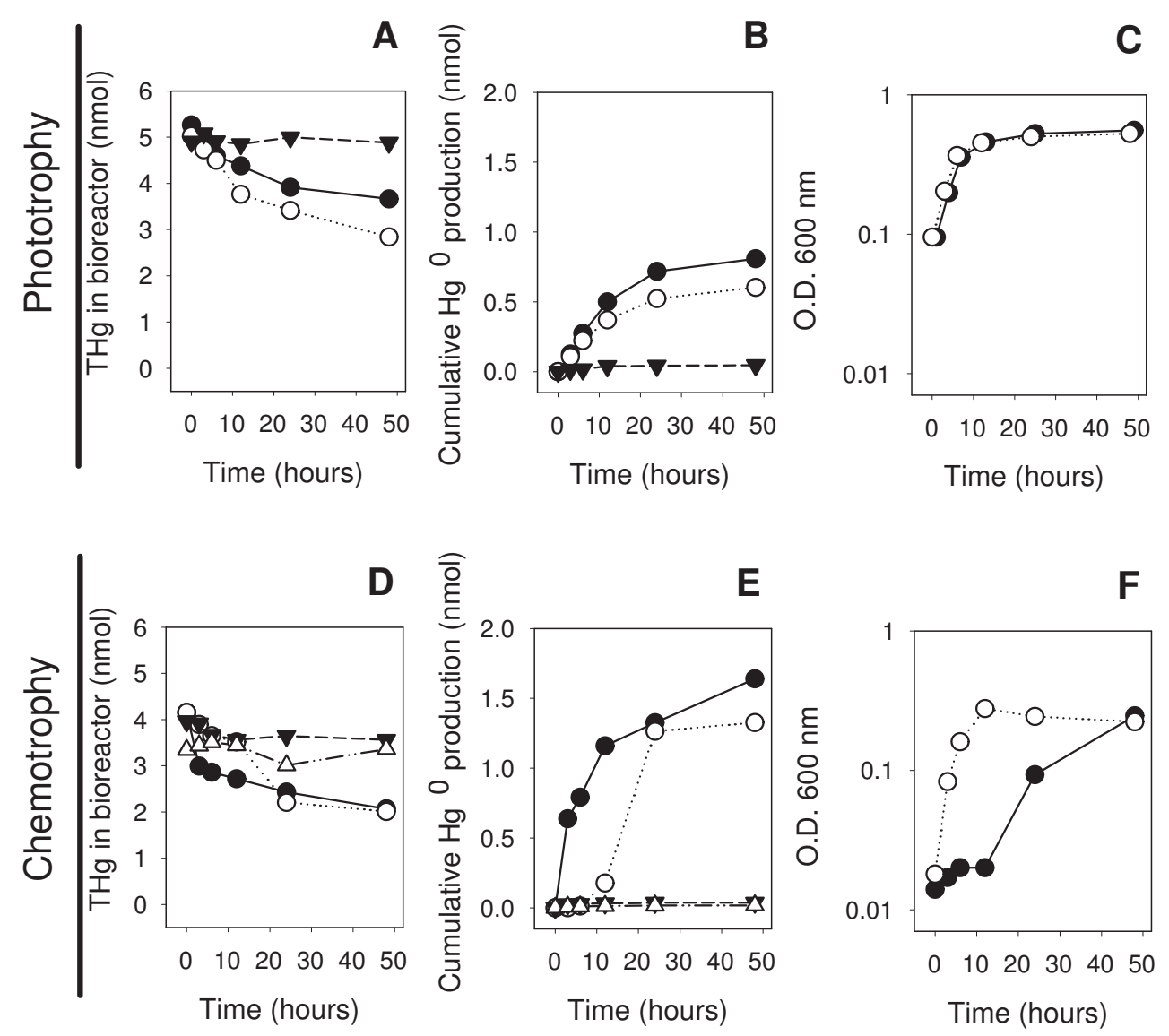

Figure 1: Total $\mathrm{Hg}$ and cumulative $\mathrm{Hg}^{0}$ production by $\mathrm{H}$. modesticaldum grown cells. B, E Cumulative $\mathrm{Hg}^{0}$ production for live cells and sterile controls without cells. $\mathbf{C}, \mathbf{F}$ Microbial growth as measured by O.D. $600 \mathrm{~nm}$ for live cells and sterile controls without cells. 10 $\mathrm{nM} \mathrm{Hg}$ was supplied in all experiments from the same stock (NIST 3133). 
Despite carefully controlling the growth conditions in our experiments, chemotrophic

250 cells from replicate \#1 exhibited a lag phase of 12 hours (Fig 1F). Although this lag did not

251 affect final cell density, the slow-growing culture from replicate \#1 initiated $\mathrm{Hg}^{0} \mathrm{production}^{-}$

252 earlier than the culture in replicate \#2 (Fig 1E, F). These results may be attributable to cells in

253 replicate \#1 maintaining a higher $\mathrm{Hg}$ to cell ratio in the first 12 hours of the experiment, which

254 suggests that $\mathrm{Hg}$ is being reduced intracellularly in line with our previous work on Heliobacteria

$255(23,50)$. Indeed, even at low initial densities, cells can maintain $\mu \mathrm{M}$ levels of intracellular

256 reducing power, which could be used to reduce $\mathrm{nM}$ levels of $\mathrm{Hg}^{\mathrm{II}}$ (24).

\section{Mass dependent fractionation during photosynthetic and fermentative growth}

$259 \mathrm{Hg}$ reduction in phototrophically grown $H$. modesticaldum resulted in consistent positive MDF

260 whereas fermentatively grown cultures showed positive MDF with variability in fractionation

261 patterns across replicates (Fig 2). Abiotic controls showed minimal fractionation for both MDF

262 and MIF, confirming that $\mathrm{Hg}$ reduction and subsequent isotopic fractionation were

263 predominantly driven by cellular processes (Fig 2). Live cell experiments were devoid of MIF

264 (Table S1 and Table S2).

265 For phototrophically-grown cultures, the reactant pool $\delta^{202} \mathrm{Hg}^{\mathrm{II}}$ increased steadily over time 266 suggesting cells preferentially reduced lighter $\mathrm{Hg}^{\mathrm{II}}$ (Fig 2A). A mirror trend was observed for

$267 \delta^{202} \mathrm{Hg}^{0}$, which was depleted in ${ }^{202} \mathrm{Hg}^{0}$ at the beginning of the experiment, became enriched with

268 heavier isotopes as the reaction proceeded, and eventually approached the initial isotopic

269 composition of the NIST 3133 standard (0\%o) (Fig 2B). 

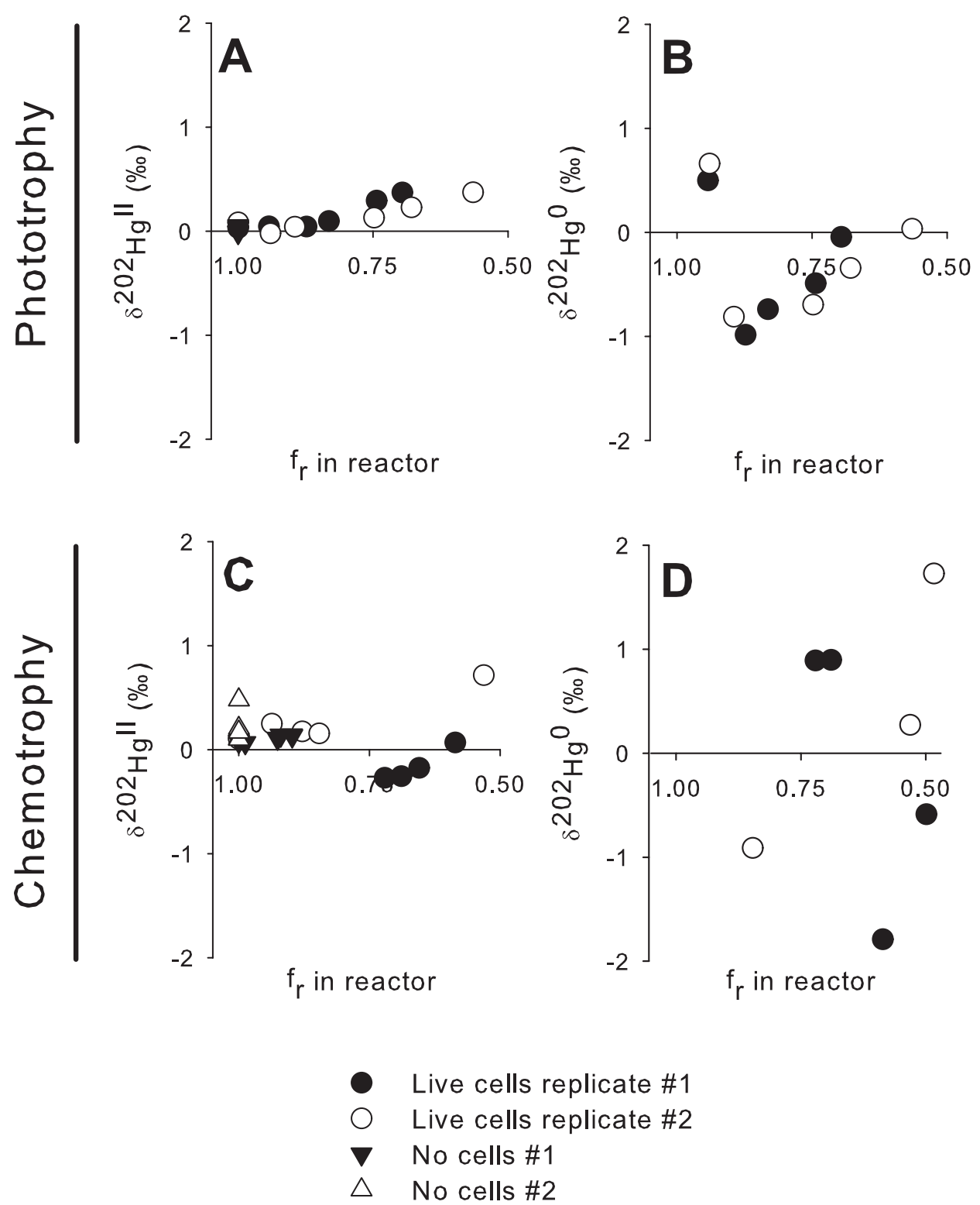

273 Figure 2: Mass dependent fractionation of ${ }^{202} \mathrm{Hg}_{\text {in }} \mathrm{Hg}^{\mathrm{II}}(\mathrm{A}, \mathrm{C})$ and $\mathrm{Hg}^{\mathbf{0}}$ (B, D) during phototrophic and chemotrophic growth of $H$. modesticaldum and no cell controls. $\delta^{202} \mathrm{Hg}$ values for $\mathrm{Hg}^{\mathrm{II}}$ and $\mathrm{Hg}^{0}$ are plotted with respect to the fraction of remaining total inorganic $\mathrm{Hg}^{\mathrm{II}}$ in the bioreactor. Insufficient $\mathrm{Hg}^{0}$ was recovered from the no cell controls and thus no results are displayed. $10 \mathrm{nM} \mathrm{Hg}$ was used in all experiments and $\mathrm{Hg}$ was supplied from the same stock (NIST 3133). 
Curiously, the $\delta^{202} \mathrm{Hg}^{0}$ for $\mathrm{f}_{\mathrm{r}}=0.94$ at $3 \mathrm{~h}$ in the two phototrophic live cell replicates showed that the product pool was initially enriched with the ${ }^{202} \mathrm{Hg}^{0}$ isotope (Fig 2B). A similar pattern

281 has been observed in iron reducing bacteria that preferentially reduced heavier Fe ${ }^{\mathrm{III}}(51)$ and the

282 model anaerobic $\mathrm{Hg}$ methylator and reducer Geobacter sulfurreducens PCA $(37,40)$. The most

283 recent work on G. sulfurreducens has shown that uptake of $\mathrm{Hg}$ selects for lighter $\mathrm{Hg}$ isotopes but

284 cells can also access an isotopically heavier pool of $\mathrm{Hg}^{\mathrm{II}}$ from the dissolved phase (37). It is

285 possible that a similar process is occurring for phototrophically-grown H. modesticaldum

286 wherein cells access an isotopically heavier pool of $\mathrm{Hg}$ during equilibrium binding of $\mathrm{Hg}^{\mathrm{II}}$ to the

287 outside of the cell, followed by an alternative uptake process that selects for lighter pools of $\mathrm{Hg}$.

288 Based on these results, we included all time points in isotopic enrichment calculations for $\mathrm{Hg}^{\mathrm{II}}$

289 but omitted the $3 \mathrm{~h}$ time point in calculations for $\mathrm{Hg}^{0}$ given that other cellular fractionation

290 processes could be occurring (Fig S3, Fig S4, and Table S3).

291 Positive MDF was also observed for chemotrophic cultures but fractionation patterns differed 292 strongly between replicates. Replicate \#1 showed an initial depletion in reactant pool $\delta^{202} \mathrm{Hg}^{\mathrm{II}}$ and 293 became progressively enriched with ${ }^{202} \mathrm{Hg}^{\mathrm{II}}$ relative to the NIST 3133 suggesting lighter isotopes 294 were still preferentially reduced (Fig 2C). Note that the second $\delta^{202} \mathrm{Hg}^{\mathrm{II}}$ data point available for 295 replicate $\# 1$ occurs at $\mathrm{f}_{\mathrm{r}}=0.72$ due to the rapid rate of $\mathrm{Hg}^{\mathrm{II}}$ reduction leading to substantially less 296 Hg remaining in the reactor (Fig 1E and Fig 2C). Results for replicate \#2 further suggested that 297 lighter $\mathrm{Hg}^{\mathrm{II}}$ isotopes were preferentially reduced with $\delta^{202} \mathrm{Hg}^{\mathrm{II}}$ slightly increasing at the 298 beginning of the experiment before rising to a maximum of $0.72 \%$ between $f_{r}=0.85$ at $12 \mathrm{~h}$ and 2990.53 at $24 \mathrm{~h}($ Fig 2C). 
The trends for $\delta^{202} \mathrm{Hg}^{0}$ in chemotrophic cultures mirrored what was observed for $\delta^{202} \mathrm{Hg}^{\mathrm{II}}$. $\delta^{202} \mathrm{Hg}^{0}$ from replicate \#1 showed that the product pool was initially enriched with heavy ${ }^{202} \mathrm{Hg}^{0}$,

303 further suggesting cells may have accessed a readily bioavailable pool of heavy $\mathrm{Hg}^{\mathrm{II}}$, before

304 undergoing a pronounced depletion and progressive enrichment with heavy isotopes similar to

305 phototrophic cultures (Fig 2B, D). In contrast, the $\delta^{202} \mathrm{Hg}^{0}$ values for cells in replicate \#2 suggest

306 that the product pool was depleted in ${ }^{202} \mathrm{Hg}^{0}$ before undergoing enrichment for heavier $\mathrm{Hg}^{0}$

307 isotopes reaching a maximum of $1.73 \%$ (Fig 2D).

308 The enrichment in ${ }^{202} \mathrm{Hg}^{0}$ exceeded the initial composition of the NIST 3133 standard (0\%o)

309 suggesting fractionation deviated from the predicted Rayleigh fractionation for $\mathrm{Hg}$ reduction

310 (Table S4). Recent work with G. sulfurreducens has shown that subcellular partitioning

311 processes contribute to $\mathrm{Hg}$ isotope fractionation and cannot be detected at the level of $\mathrm{THg}$ pool

312 (37). In our work, $\mathrm{Hg}$ reduction provided such a strong isotopic shift that we could detect

313 fractionation in the $\mathrm{THg}$ pool, however we cannot discount the contributions of subcellular

314 partitioning processes, which are smaller in magnitude $(<0.10 \%)$. Such processes could be

315 driving the depletion of ${ }^{202} \mathrm{Hg}^{\mathrm{II}}$ early on for chemotrophic cells in replicate \#1 where low cell

316 densities may have amplified uptake and adsorption-driven fractionation (Fig 1F). It is more

317 challenging to discuss contributions of such processes for replicate $\# 2$, where the low cumulative

$318 \mathrm{Hg}^{0}$ production at $\mathrm{f}_{\mathrm{r}}=0.94$ and 0.88 ( $3 \mathrm{~h}$ and $6 \mathrm{~h}$ time points, respectively) precluded our ability to

319 measure $\mathrm{Hg}^{0}$ isotope fractionation (Fig 1E and Table S2). Despite this limitation, the high

$320 \delta^{202} \mathrm{Hg}^{0}$ value obtained for the final timepoint for replicate \#2 reinforces that additional processes

321 are contributing to fractionation under chemotrophic conditions that warrant further exploration. 
Our experimental results suggest that $\mathrm{Hg}^{0}$ oxidation is not a major contributor at earlier

324 stages of reduction (i.e., 3-12 hours) but may be contributing to isotope fractionation at later time

325 points associated with longer $\mathrm{Hg}$ residence times in the reactor. Under phototrophic conditions,

326 the measured values of $\delta^{202} \mathrm{Hg}^{\mathrm{II}}$ at $48 \mathrm{~h}$ were isotopically heavier than predicted values, which

327 suggests $\mathrm{Hg}^{0}$ oxidation may be occurring (Table S4). Under fermentative conditions the

328 potential contribution of $\mathrm{Hg}$ oxidation is unclear, since a consistent enrichment was not observed

329 between replicates (Table S4). The variability in isotope results for later time points in both

330 replicates suggests processes other than reduction may be occurring.

331 Although $\mathrm{Hg}^{0}$ oxidation has never been observed in anoxygenic phototrophs, it has been

332 observed in other model chemotrophic anaerobes (49). Recent work showed that thiol-bearing

333 molecules preferentially oxidize heavy ${ }^{202} \mathrm{Hg}^{0}$, leading to negative MDF, in addition to a MIF

334 signal (52). Although we did not observe any negative MDF or MIF in our experiments (Table

335 S1 and Table S2), we acknowledge that such processes have the potential to contribute to net

336 fractionation alongside internal partitioning related to uptake or adsorption processes. These

337 results are an important first step to resolving the physiological processes that drive these $\mathrm{Hg}$

338 transformations in H. modesticaldum and we plan to carry out additional experiments to assess

339 the contributions of uptake, adsorption, and redox transformations to the net $\mathrm{Hg}$ isotope

340 fractionation observed in the future. 


\section{Comparing enrichment factors for abiotic and biotic Hg transformations}

344 The average isotopic enrichment factor calculated using the ratio of product to reactant $\left(\varepsilon_{\mathrm{p} / \mathrm{r}}\right) \pm 2$

345 standard deviations (2SD) for MDF in the reactant pool $\mathrm{Hg}^{\mathrm{II}}$ during anoxygenic photosynthesis

$346\left(\varepsilon_{\mathrm{AP}}\right)$ was $-0.80 \pm 0.56 \%$ whereas the average isotopic enrichment factor obtained during

347 fermentation $\left(\varepsilon_{\mathrm{FM}}\right)$ was $-1.13 \pm 0.50 \%$ (Fig 3, Fig S3, Table S3, and Table S5).

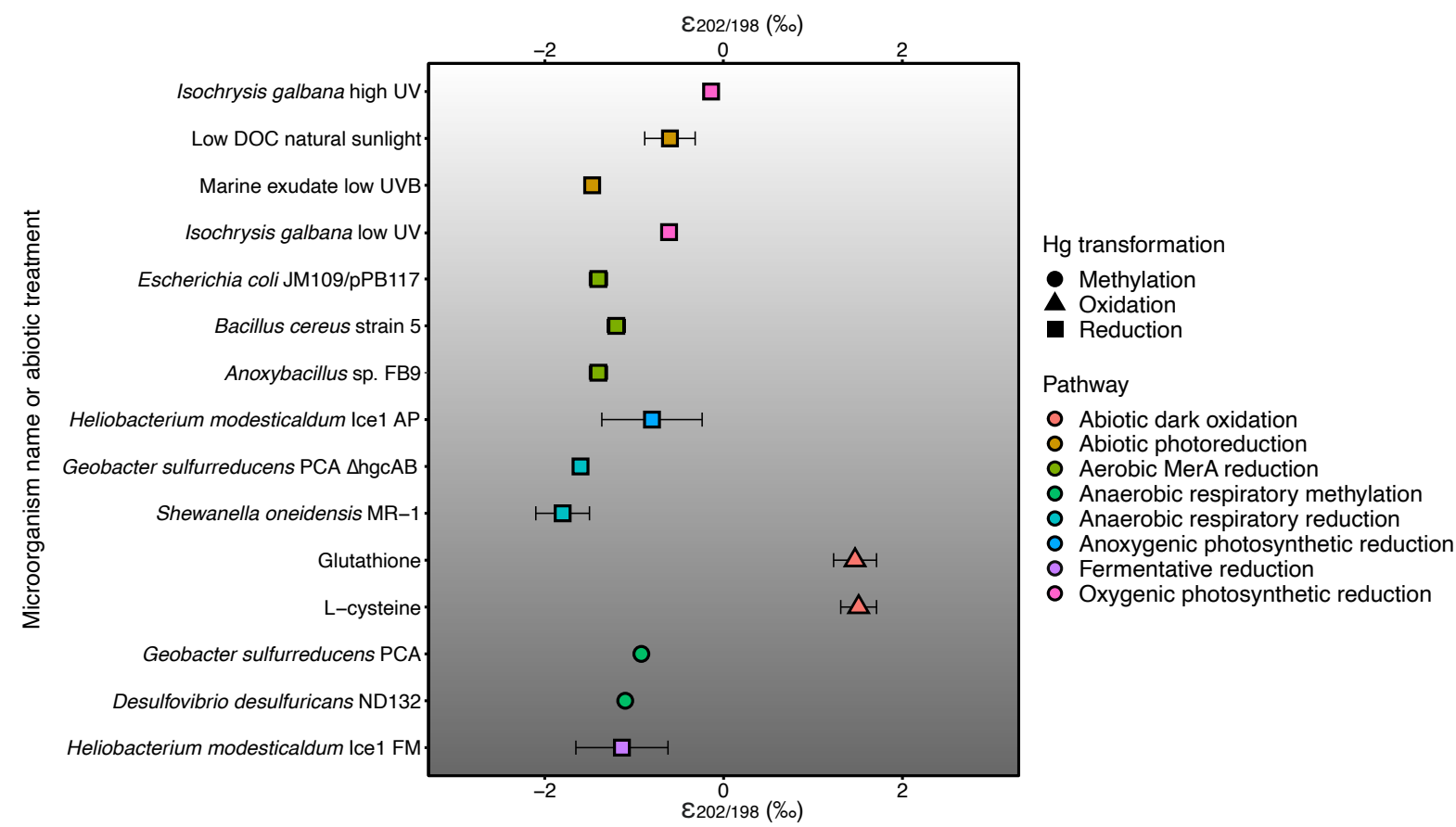

349 Figure 3: Compilation of isotopic enrichment factors ( $)$ for abiotic and biotic $\mathbf{H g}$

350 transformations. $\mathrm{Hg}$ transformations are denoted by different shapes and specific metabolic and chemical pathways have been colour coded. Error bars denote 2 standard deviations for studies where this data was available. In the event that data was presented as a standard error, standard deviation was calculated based on the sample size indicated in each study. Abbreviations on the y-axis denote the following: UV (ultraviolet light), DOC (dissolved organic carbon), AP (anoxygenic photosynthesis), $\triangle$ hgcAB (no hgcAB gene cluster), and FM (fermentation). The grey-shading in this figure represents light and oxygen. Lighter regions represent habitats where light and oxygen are present and darker regions represent where they are not. The values in this figure were obtained from the following studies: abiotic dark oxidation (52); abiotic photoreduction $(32,41)$; aerobic MerA reduction $(34,36)$; anaerobic respiratory methylation

360 (40); anaerobic respiratory reduction $(36,37)$; anoxygenic photosynthetic reduction (this study); 361 fermentative reduction (this study); oxygenic photosynthetic reduction (41). The raw data in this 362 figure are in Table S5. 
363 The enrichment factor could not be calculated using the product $\mathrm{Hg}^{0}$ pool for fermentative

364 cultures and overestimated the value in phototrophic cultures (-2.86 $\pm 1.32 \%$ ) (Fig S4 and

365 Table S3). Previous work has shown that using the product pool can overestimate the

366 fractionation factor due to difficulty obtaining analytical replicates of gaseous $\mathrm{Hg}^{0}$ and the

367 complexity of quantitatively collecting this pool (53). As such, we carried out comparisons for

368 enrichment factors using the reactant $\mathrm{Hg}^{\mathrm{II}}$ pool. Ideally, we would have been able to obtain more

369 replicates of our experiments but were unable to do so due the challenges stated previously. It is

370 important to note that low numbers of replicates are routinely discussed in isotope geochemistry

371 and the variability from our results is in line with previous work (Fig 3 and Table S5).

372 Our initial motivation for this study was to test if phototrophic and fermentative $\mathrm{Hg}$

373 reduction led to markedly different isotope enrichment factors and establish whether different

374 underlying processes supported different metabolic Hg reduction pathways. When comparing $\varepsilon$

375 values, which are used as an index to distinguish between different isotope fractionation

376 processes, we report a difference of $0.33 \%$ between $\varepsilon_{\mathrm{AP}}$ and $\varepsilon_{\mathrm{FM}}($ Fig 3 and Table S5). This

377 small difference in enrichment factors supports that common processes are controlling $\mathrm{Hg}$

378 reduction during anoxygenic photosynthesis and fermentation in H. modesticaldum.

In our previous work with $H$. modesticaldum we demonstrated that inhibiting pyruvate

380 ferredoxin oxidoreductase, the enzyme responsible for the production of reduced ferredoxin,

381 greatly hampered $\mathrm{Hg}^{\mathrm{II}}$ reduction during anoxygenic photosynthesis and fermentation (23). It is

382 possible that the similarity between $\varepsilon_{\mathrm{AP}}$ and $\varepsilon_{\mathrm{FM}}$ is the result of reactions originally involving the

383 same redox cofactors (e.g. ferredoxins) but with $\mathrm{Hg}^{\mathrm{II}}$ being reduced by different electron donors

384 specific to each metabolism. Such reactions could involve direct electron transfer from

385 ferredoxin to $\mathrm{Hg}^{\mathrm{II}}$ or from enzymes directly or indirectly relying on ferredoxin $(23,54)$. It is also 
386 possible that the net isotopic enrichment stems from a combination of multiple processes

387 involved in $\mathrm{Hg}$ transport (e.g. adsorption, uptake, and efflux) that would occur regardless of the

388 intracellular transformations in question. Our results suggest that the relative contributions of

389 these processes may be more pronounced during fermentation compared to anoxygenic

390 photosynthesis although more controlled experiments are required to constrain the variability in

391 the isotope fractionation observed.

392 At the broader scale, the isotopic enrichment observed for both metabolisms tested in $H$.

393 modesticaldum falls between the values observed for abiotic and microbial $\mathrm{Hg}$ reduction

394 pathways (Fig 3 and Table S5). The isotopic enrichment observed for phototrophic $H$.

395 modesticaldum is slightly lower than photoreduction in the presence of dissolved organic carbon

$396(-0.80 \pm 0.56 \%$ vs $-0.60 \pm 0.20 \%$, respectively) (32) but higher than photoreduction in the

397 presence of marine exudates and UVB light (-0.80 $\pm 0.56 \%$ vs $-1.47 \%$, respectively) (41) (Fig

3983 and Table S5). When comparing Hg reduction in the anoxygenic phototroph H. modesticaldum

399 to the oxygenic phototrophic green alga Isochrysis galbana, the isotopic enrichment observed is

400 also slightly lower (-0.80 $\pm 0.56 \%$ vs -0.14 to $-0.60 \%$, respectively) (41) (Fig 3 and Table S5).

401 Though this similarity suggests anoxygenic and oxygenic photosynthetic $\mathrm{Hg}$ reduction share a

402 common physiological pathway, the presence of MIF in I. galbana due to free radical generation

403 within the cell rules out this possibility (41). (Table S1). Thus, Hg reduction during anoxygenic

404 photosynthetic $\mathrm{Hg}$ reduction could be distinguished from other photo-induced reduction

405 pathways due to the lack of MIF tracer. 
When compared with previous work on microbial $\mathrm{Hg}$ reduction in pure cultures, the isotopic enrichment observed for phototrophically-grown H. modesticaldum was higher than what has previously been reported for aerobic mer-mediated reduction and anaerobic respiratory $\mathrm{Hg}$

410 reduction $(-0.80 \pm 0.56 \%$ vs -1.80 to $-1.20 \%$, respectively) $(34,36,37)$ (Fig 3 and Table S5).

411 Interestingly, the isotopic enrichment observed in fermentatively-grown $H$. modesticaldum (-1.13

$412 \pm 0.50 \%$ ) was closer to aerobic mer-mediated reduction (-1.40 to $-1.20 \%$ ) (34) than to

413 anaerobic respiratory $\mathrm{Hg}$ reduction in Shewanella oneidensis MR-1 and a modified strain of $G$.

414 sulfurreducens PCA incapable of $\mathrm{Hg}$ methylation (-1.80 to -1.60 \%o) (Fig 3 and Table S5) (36,

$41537)$. An additional line of evidence supporting that $\mathrm{Hg}^{0}$ oxidation is unlikely to be contributing to

416 the isotope signature observed in our system are the $\varepsilon$ values for thiol mediated $\mathrm{Hg}^{0}$ oxidation in

417 the dark. These values are considerably larger than what we observed for H. modesticaldum

418 (1.51 $\pm 0.20 \%$ for cysteine and $1.47 \pm 0.24 \%$ for glutathione) (Fig 3 and Table S5).

These comparisons illustrate that isotopic enrichment for microbial $\mathrm{Hg}$ reduction

420 pathways that only display MDF fall within a narrow range (i.e. -0.80 to $-1.80 \%$ ) (Fig 3 and

421 Table S5). We find this to be a strikingly small difference given the ecological diversity of the

422 model organisms and variety of growth conditions used to study microbial $\mathrm{Hg}$ reduction. The

423 similar $\varepsilon$ values reported for fermentation in this study and the mer operon are also noteworthy as

424 they suggest nearly identical isotope enrichment can occur in aerobes harbouring dedicated

425 enzymatic machinery to reduce $\mathrm{Hg}$ and anaerobes where mer-based strategies are largely absent.

426 Our study also shows that similar isotopic enrichment can be observed for different

427 anaerobic $\mathrm{Hg}$ transformations. The anaerobic $\mathrm{Hg}$ methylating chemotrophs G. sulfurreducens

428 PCA and Desulfovibrio desulfuricans ND132 displayed $\varepsilon$ signatures (i.e. -0.92 and -1.1\%,

429 respectively) that fall within the range of $\varepsilon$ values we report in our study (i.e. -0.80 to $-1.13 \%$ ) 
430 (Fig 3 and Table S5) (40). The similarity in enrichment signatures suggests that common

431 processes may affect the delivery of inorganic $\mathrm{Hg}$ substrates to intracellular sites independently

432 of the Hg transformations in question. Although it is outside of the scope of the current study,

433 identifying the nature of these processes may provide insights into similar controls that exist for

$434 \mathrm{Hg}$ uptake and transformation in anaerobes.

435 Our work showcases the strengths but also the challenges of using isotope fractionation-

436 based approaches to decipher cryptic Hg cycling pathways. To illustrate the challenges of using

437 isotopes to track $\mathrm{Hg}$ cycling pathways in the environment, we visualized our comparison of $\varepsilon$

438 values in the context of a vertically redox stratified habitat (e.g. a water column) (Fig 3).

439 Through $\mathrm{Hg}$ stable isotope fractionation, we can distinguish between abiotic and biotic redox

440 reaction pathways that control $\mathrm{Hg}$ 's availability in methylation hotspots, such as the limit of the

441 photic zone, on the bases of MIF signatures associated with photochemical reactions. In contrast,

442 teasing apart biological pathways that contribute to the net isotope signature of $\mathrm{Hg}^{\mathrm{II}}$ in the

443 environment is more challenging because competing MDF processes occur in both dark and

444 photo-mediated pathways where $\mathrm{Hg}^{\mathrm{II}}$ is a reactant (e.g. reduction and methylation) and a product

445 (e.g. demethylation and oxidation). This overlap makes it difficult to translate $\delta^{202} \mathrm{Hg}$ values

446 observed under controlled conditions that are sensitive to changes in cellular physiology to

447 environments where pools of bioavailable $\mathrm{Hg}$ are not homogenous due to variable mixing.

\section{CONCLUSION}

450 In this study we have provided the first evidence that common physiological processes drive

451 MDF during $\mathrm{Hg}$ reduction associated with anoxygenic photosynthesis and fermentation in the

452 model anaerobe $H$. modesticaldum. We show that isotopic enrichment during anoxygenic 
453 phototrophic $\mathrm{Hg}$ reduction leads to an intermediate fractionation process that lies between

454 photochemical reactions and dark microbial $\mathrm{Hg}$ reduction. We also show that fermentative $\mathrm{Hg}$

455 reduction leads to isotopic enrichment that is similar to aerobic mer-mediated reduction.

456 Although current analytical capacities to measure stable isotope fractionation make

457 applying such approaches to the environment challenging, this is a burgeoning field that has

458 advanced considerably in terms of sensitivity and the different $\mathrm{Hg}$ species that can be targeted in

459 the last 10 years. Isotope fractionation approaches have proved extremely valuable for teasing

460 apart the complex interwoven processes that drive microbe-mediated $\mathrm{Hg}$ transformations and as

461 seen in our study, highlighting common processes that control $\mathrm{Hg}$ bioavailability to microbes.

In future work, it will be important to isolate the different steps involved in $\mathrm{Hg}$ uptake

463 and transformation by rigorously controlling $\mathrm{Hg}$ availability and cellular physiology. Leveraging

464 molecular tools alongside isotopes will be a useful strategy to address these knowledge gaps and

465 the recent availability of genetically tractable $H$. modesticaldum deletion mutants offers a

466 promising means to do so (55). In that regard, gene deletion approaches targeting redox-active

467 enzymes could be used to characterize the physiological components contributing directly to $\mathrm{Hg}^{\mathrm{II}}$

468 reduction, whereas targeting homologues for proteins involved in $\mathrm{Hg}$ uptake in other model

469 anaerobes could be the key to identifying entry routes for $\mathrm{Hg}$ into $\mathrm{H}$. modesticaldum $(56,57)$.

470 In addition to gene deletions, whole-genome, transcriptome, and proteome approaches

471 could be combined with isotopic analyses in pure cultures to hone in on potential biomarkers for

$472 \mathrm{Hg}$ transformation pathways that remain poorly understood. Such biomarkers could be used to

473 examine publicly available genomic datasets to assess the distribution of anaerobic $\mathrm{Hg}$ reducers

474 in modern day environments and rock records, the latter serving as an archive for $\mathrm{Hg}$ isotope

475 signatures and the microbial community involved in historical $\mathrm{Hg}$ cycling $(31,58)$. These ancient 
476 environments were likely dominated by anoxygenic phototrophs that were important primary

477 producers before the rise of oxygen on Earth. By using isotopes to create a window into the past,

478 we can compare the selective forces that gave rise to fortuitous $\mathrm{Hg}$ reduction pathways tied to

479 anaerobic metabolisms and dedicated detoxification strategies such as the mer operon.

\section{ACKNOWLEDGMENTS}

482 Our work was funded by NSERC Discovery and Accelerator grants, CFI funding to AJP and

483 NSERC graduate scholarship to DSG. Instrumentation and lab operations for Hg isotope

484 analyses were supported by the USGS Toxic Substances Hydrology Program. Any use of trade,

485 firm, or product names is for descriptive purposes only and does not imply endorsement by the

486 U.S. Government.

\section{AUTHOR CONTRIBUTIONS}

490 experiments and data analyses; SEJ and MTT carried out total Hg and stable isotope analyses;

491 DSG, AJP, SEJ and MTT wrote the manuscript. 


\section{REFERENCES}

494 1. Selin NE. 2009. Global biogeochemical cycling of mercury: A review. Annual Review of 495 Environment and Resources 34:43-63.

496 2. Parks JM, Johs A, Podar M, Bridou R, Hurt Jr RA, Smith SD, Tomanicek SJ, Qian Y, 497 Brown SD, Brandt CC, Palumbo AV, Smith JC, Wall JD, Elias DA, Liang L. 2013. The 498 genetic basis for bacterial mercury methylation. Science 339:1332-1335.

499 3. Fleming EJ, Mack EE, Green PG, Nelson DC. 2006. Mercury methylation from unexpected sources: Molybdate-inhibited freshwater sediments and an iron-reducing bacterium. Applied and Environmental Microbiology 72:457-464.

502 4. Han S, Narasingarao P, Obraztsova A, Gieskes J, Hartmann AC, Tebo BM, Allen EE, Deheyn DD. 2010. Mercury speciation in marine sediments under sulfate-limited conditions. Environmental Science and Technology 44:3752-3757.

505 5. Podar M, Gilmour CC, Brandt CC, Soren A, Brown SD, Crable BR, Palumbo AV, 506 Somenahally AC, Elias DA. 2015. Global prevalence and distribution of genes and microorganisms involved in mercury methylation. Science Advances 1:1-13.

508 6. Schartup AT, Balcom PH, Soerensen AL, Gosnell KJ, Calder RS, Mason RP, Sunderland EM. 2015. Freshwater discharges drive high levels of methylmercury in Arctic marine biota. Proceedings of the National Academy of Sciences of the United States of America 112:11789-94.

512 7. Hsu-Kim H, Kucharzyk KH, Zhang T, Deshusses MA. 2013. Mechanisms regulating mercury bioavailability for methylating microorganisms in the aquatic environment: a critical review. Environmental Science and Technology 47:2441-56. 
515 8. Gustin MS, Biester H, Kim CS. 2002. Investigation of the light-enhanced emission of mercury from naturally enriched substrates. Atmospheric Environment 36:3241-3254.

517 9. Amyot M, Lean D, Mierle G. 1997. Photochemical formation of volatile mercury in high

518 Arctic lakes. Environmental Toxicology and Chemistry 16:2054-2063.

519 10. Whalin L, Kim EH, Mason R. 2007. Factors influencing the oxidation, reduction, 520 methylation and demethylation of mercury species in coastal waters. Marine Chemistry $521 \quad 107: 278-294$.

522 11. Poulain AJ, Amyot M, Findlay D, Findlay S, Telor S, Barkay T, Hintelmann H, Amyot 523 M, Findlay D. 2011. Biological and photochemical production of dissolved gaseous 524 mercury in a boreal lake. Limnology 49:2265-2275.

525 12. Carpi A, Lindberg SE. 1997. Sunlight-mediated emission of elemental mercury from soil amended with municipal sewage sludge. Environmental Science and Technology 31:2085-2091.

528 13. Vandal GM, Fitzgerald WF, Rolfhus KR, Lamborg CH. 1995. Modeling the elemental mercury cycle in Pallette Lake, Wisconsin, USA. Water, air, and soil pollution 80:529$530 \quad 538$.

531 14. Zhang H, Lindberg SE. 2001. Sunlight and iron(III)-induced photochemical production of dissolved gaseous mercury in freshwater. Environmental Science and Technology 35:928-935.

534 15. Zhang H. 2006. Photochemical redox reactions of mercury, p 37-79. In Atwood DA (ed), Recent Developments in Mercury Science, vol 120. 
536 16. O'Driscoll NJ, Lean DRS, Loseto LL, Carignan R, Siciliano SD. 2004. Effect of dissolved organic carbon on the photoproduction of dissolved gaseous mercury in lakes: Potential impacts of forestry. Environmental Science and Technology 38:2664-2672.

539 17. Gu B, Bian Y, Miller CL, Dong W, Jiang X, Liang L. 2011. Mercury reduction and complexation by natural organic matter in anoxic environments. Proceedings of the National Academy of Sciences of the United States of America 108:1479-1483.

542 18. Wiatrowski HA, Das S, Kukkadapu R, Ilton ES, Barkay T, Yee N. 2009. Reduction of $\mathrm{Hg}(\mathrm{II})$ to $\mathrm{Hg}(0)$ by magnetite. Environmental Science and Technology 43:5307-5313.

544 19. Bone SE, Bargar JR, Sposito G. 2014. Mackinawite (FeS) reduces mercury(II) under sulfidic conditions. Environmental Science and Technology 48:10681-10689.

20. Wiatrowski HA, Ward PM, Barkay T. 2006. Novel reduction of mercury(II) by mercurysensitive dissimilatory metal reducing bacteria. Environmental Science and Technology 40:6690-6696.

21. Lu X, Liu Y, Johs A, Zhao L, Wang T, Yang Z, Lin H, Elias DA, Pierce EM, Liang L, Barkay T, Gu B. 2016. Anaerobic mercury methylation and demethylation by Geobacter bemidjiensis Bem. Environmental Science and Technology 50:4366-4373.

22. Lin H, Morrell-Falvey JL, Rao B, Liang L, Gu B. 2014. Coupled mercury-cell sorption, reduction, and oxidation on methylmercury production by Geobacter sulfurreducens

555 23. Grégoire DS, Lavoie NC, Poulain AJ. 2018. Heliobacteria reveal fermentation as a key pathway for mercury reduction in anoxic environments. Environmental Science and Technology 52:4145-4153. 
558 24. Grégoire DS, Poulain AJ. 2016. A physiological role for $\mathrm{Hg}(\mathrm{II})$ during phototrophic 559 growth. Nature Geoscience 9:121-125.

560 25. Barkay T, Kritee K, Boyd E, Geesey G. 2010. A thermophilic bacterial origin and 561 subsequent constraints by redox, light and salinity on the evolution of the microbial 562 mercuric reductase. Environmental Microbiology 12:2904-2917.

563 26. Grégoire DS, Poulain AJ. 2014. A little bit of light goes a long way: the role of phototrophs on mercury cycling. Metallomics 6:396-407.

565 27. Poulin BA, Aiken GR, Nagy KL, Monceau A, Krabbenhoft DP, Ryan JN. 2016. Mercury transformation and release differs with depth and time in a contaminated riparian soil during simulated flooding. Geochimica Et Cosmochimica Acta 176:118-138.

568 28. Bouffard A, Amyot M. 2009. Importance of elemental mercury in lake sediments. $569 \quad$ Chemosphere 74:1098-1103.

570 29. Grégoire DS, Poulain AJ. 2018. Shining light on recent advances in microbial mercury cycling. FACETS 3:858-879.

572 30. Blum JD, Sherman LS, Johnson MW. 2014. Mercury isotopes in earth and environmental 573 sciences. Annual Review of Earth and Planetary Sciences 42:249-269.

574 31. Zheng W, Gilleaudeau GJ, Kah LC, Anbar AD. 2018. Mercury isotope signatures record 575 photic zone euxinia in the Mesoproterozoic ocean. Proceedings of the National Academy of Sciences 115:10594-10599.

577 32. Bergquist BA, Blum JD. 2007. Mass-dependent and -independent fractionation of $\mathrm{Hg}$ 578 isotopes by photoreduction in aquatic systems. Science 318:417-420.

579 33. Bergquist BA, Blum JD. 2009. The odds and evens of mercury isotopes: Applications of mass-dependent and mass-independent isotope fractionation. Elements 5:353-357. 
581 34. Kritee K, Blum JD, Johnson MW, Bergquist BA, Barkay T. 2007. Mercury stable isotope fractionation during reduction of $\mathrm{Hg}(\mathrm{II})$ to $\mathrm{Hg}(0)$ by mercury resistant microorganisms. Environmental Science and Technology 41:1889-1895.

584 35. Kritee K, Barkay T, Blum JD. 2009. Mass dependent stable isotope fractionation of mercury during mer mediated microbial degradation of monomethylmercury. Geochimica et Cosmochimica Acta 73:1285-1296.

36. Kritee K, Blum JD, Barkay T. 2008. Mercury stable isotope fractionation during reduction of $\mathrm{Hg}(\mathrm{II})$ by different microbial pathways. Environmental Science and

37. Wang Y, Janssen SE, Schaefer JK, Yee N, Reinfelder JR. 2020. Tracing the uptake of $\mathrm{Hg}(\mathrm{II})$ in an iron-reducing bacterium using mercury stable isotopes. Environmental

38. Rodríguez-González P, Epov VN, Bridou R, Tessier E, Guyoneaud R, Monperrus M, Amouroux D. 2009. Species-specific stable isotope fractionation of mercury during $\mathrm{Hg}(\mathrm{II})$ methylation by an anaerobic bacteria (Desulfobulbus propionicus) under dark

39. Perrot V, Bridou R, Pedrero Z, Guyoneaud R, Monperrus M, Amouroux D. 2015. sulfate-reducing bacteria in sulfate and sulfate-free environment. Environmental Science and Technology 49:1365-1373.

40. Janssen SE, Schaefer JK, Barkay T, Reinfelder JR. 2016. Fractionation of mercury stable isotopes during microbial methylmercury production by iron- and sulfate-reducing bacteria. Environmental Science and Technology 50:8077-8083. 
604 41. Kritee K, Motta LC, Blum JD, Tsui MT-K, Reinfelder JR. 2018. Photomicrobial visible light-induced magnetic mass independent fractionation of mercury in a marine microalga. ACS Earth and Space Chemistry 2:432-440.

607 42. EPA U. 2002. Method 1631, Revision E: Mercury in water by oxidation, purge and trap, and cold vapor atomic fluorescence spectrometry. US Environmental Protection Agency

43. Janssen SE, Lepak RF, Tate MT, Ogorek JM, DeWild JF, Babiarz CL, Hurley JP, Krabbenhoft DP. 2019. Rapid pre-concentration of mercury in solids and water for

44. Yin R, Krabbenhoft DP, Bergquist BA, Zheng W, Lepak RF, Hurley JP. 2016. Effects of mercury and thallium concentrations on high precision determination of mercury isotopic

45. Blum JD, Bergquist BA. 2007. Reporting of variations in the natural isotopic composition by Neptune Plus multiple collector inductively coupled plasma mass

619 46. Lepak RF, Yin R, Krabbenhoft DP, Ogorek JM, DeWild JF, Holsen TM, Hurley JP. 2015. Use of stable isotope signatures to determine mercury sources in the Great Lakes.

$621 \quad$ Environmental Science \& Technology Letters 2:335-341.

622 47. Tang KH, Feng XY, Zhuang WQ, Alvarez-Cohen L, Blankenship RE, Tang YJ. 2010. 623 Carbon flow of Heliobacteria is related more to Clostridia than to the Green Sulfur 
625 48. Colombo MJ, Ha J, Reinfelder JR, Barkay T, Yee N. 2013. Anaerobic oxidation of $\operatorname{Hg}(0)$ and methylmercury formation by Desulfovibrio desulfuricans ND132. Geochimica et Cosmochimica Acta 112:166-177.

628 49. Colombo MJ, Ha J, Reinfelder JR, Barkay T, Yee N. 2014. Oxidation of $\operatorname{Hg}(0)$ to $\mathrm{Hg}(\mathrm{II})$ by diverse anaerobic bacteria. Chemical Geology 363:334-340.

630 50. Lavoie NC, Grégoire DS, Stenzler BR, Poulain AJ. 2020. Reduced sulphur sources favour $\mathrm{Hg}(\mathrm{II})$ reduction during anoxygenic photosynthesis by Heliobacteria. Geobiology 18:70-79.

51. Icopini GA, Anbar AD, Ruebush SS, Tien M, Brantley SL. 2004. Iron isotope fractionation during microbial reduction of iron: The importance of adsorption. Geology

52. Zheng W, Demers JD, Lu X, Bergquist BA, Anbar AD, Blum JD, Gu B. 2019. Mercury stable isotope fractionation during abiotic dark oxidation in the presence of thiols and

53. Kritee K, Blum JD, Reinfelder JR, Barkay T. 2013. Microbial stable isotope fractionation of mercury: A synthesis of present understanding and future directions. Chemical

642 54. Tang KH, Yue H, Blankenship RE. 2010. Energy metabolism of Heliobacterium modesticaldum during phototrophic and chemotrophic growth. Bmc Microbiology 10:150

644 55. Baker PL, Orf GS, Kevershan K, Pyne ME, Bicer T, Redding KE. 2019. Using the endogenous CRISPR-Cas system of Heliobacterium modesticaldum to delete the photochemical reaction center core subunit gene. Applied and Environmental Microbiology 85:e01644-19. 
648 56. Stenzler B, Hinz A, Ruuskanen M, Poulain AJ. 2017. Ionic strength differentially affects

649 the bioavailability of neutral and negatively charged inorganic $\mathrm{Hg}$ complexes.

650 Environmental Science and Technology 51:9653-9662.

651 57. Schaefer JK, Szczuka A, Morel FM. 2014. Effect of divalent metals on Hg(II) uptake and

652 methylation by bacteria. Environmental Science and Technology 48:3007-13.

653 58. Ruuskanen MO, Aris-Brosou S, Poulain AJ. 2020. Swift evolutionary response of

654 microbes to a rise in anthropogenic mercury in the Northern Hemisphere. The ISME

655 Journal 14:788-800.

656

657 


\section{FIGURE CAPTIONS}

659 Figure 1: Total $\mathrm{Hg}$ and cumulative $\mathrm{Hg}^{\mathbf{0}}$ production by $\mathrm{H}$. modesticaldum grown

660 phototrophically and chemotrophically. A, D THg for live cells and sterile controls without

661 cells. B, E Cumulative $\mathrm{Hg}^{0}$ production for live cells and sterile controls without cells. C, F

662 Microbial growth as measured by O.D. $600 \mathrm{~nm}$ for live cells and sterile controls without cells. 10

$663 \mathrm{nM} \mathrm{Hg}$ was supplied in all experiments from the same stock (NIST 3133).

Figure 2: Mass dependent fractionation of ${ }^{202} \mathrm{Hg}_{\text {in }} \mathrm{Hg}^{\mathrm{II}}(\mathrm{A}, \mathrm{C})$ and $\mathrm{Hg}^{0}(\mathrm{~B}, \mathrm{D})$ during

phototrophic and chemotrophic growth of $\boldsymbol{H}$. modesticaldum and no cell controls. $\delta^{202} \mathrm{Hg}$ values for $\mathrm{Hg}^{\mathrm{II}}$ and $\mathrm{Hg}^{0}$ are plotted with respect to the fraction of remaining total inorganic $\mathrm{Hg}^{\mathrm{II}}$ in the bioreactor. Insufficient $\mathrm{Hg}^{0}$ was recovered from the no cell controls and thus no results are displayed. $10 \mathrm{nM} \mathrm{Hg}$ was used in all experiments and $\mathrm{Hg}$ was supplied from the same stock (NIST 3133).

673 transformations. Hg transformations are denoted by different shapes and specific metabolic and

674 chemical pathways have been colour coded. Error bars denote 2 standard deviations for studies

675 where this data was available. In the event that data was presented as a standard error, standard

676 deviation was calculated based on the sample size indicated in each study. Abbreviations on the

677 y-axis denote the following: UV (ultraviolet light), DOC (dissolved organic carbon), AP

678 (anoxygenic photosynthesis), $\Delta \mathrm{hgcAB}$ (no $h g c A B$ gene cluster), and FM (fermentation). The

679 grey-shading in this figure represents light and oxygen. Lighter regions represent habitats where

680 light and oxygen are present and darker regions represent where they are not. The values in this 
681 figure were obtained from the following studies: abiotic dark oxidation (52); abiotic

682 photoreduction $(32,41)$; aerobic MerA reduction $(34,36)$; anaerobic respiratory methylation

683 (40); anaerobic respiratory reduction $(36,37)$; anoxygenic photosynthetic reduction (this study);

684 fermentative reduction (this study); oxygenic photosynthetic reduction (41). The raw data in this

685 figure are in Table S5.

\section{SUPPORTING INFORMATION CAPTIONS}

688 Figure S1: Schematic of the bioreactor setup used to measure Hg stable isotope fractionation for $\mathrm{Hg}^{\mathrm{II}}$ and $\mathrm{Hg}^{0}$ during the anaerobic reduction of $\mathrm{Hg}^{\mathrm{II}}$. system Rayleigh fractionation models with $\ln \left(R / R_{0}\right)$ vs $\ln \left(f_{r}\right)$. The amount of $H g^{I I}$ remaining in the reactor was used to calculate $\mathrm{f}_{\mathrm{r}}$ (see Methods). The $0 \mathrm{~h}$ time point for chemotrophic live cells replicate \#1 was omitted from the regression fitted to the data for $\operatorname{Hg}^{\mathrm{II}}(\mathrm{C})$ as this suggested an alternative process was contributing to isotopic fractionation earlier on in the experiment. 


\section{Figure S4: Mass dependent fractionation of ${ }^{202} \mathbf{H g}^{\mathbf{0}}$ in phototrophically (A, B) and}

703 chemotrophically (C, D) grown $\boldsymbol{H}$. modesticaldum. $\delta^{202} \mathrm{Hg}$ values for $\mathrm{Hg}^{0}$ are plotted as open

704 system Rayleigh fractionation models with $\ln \left(\mathrm{R} / \mathrm{R}_{0}\right)$ vs $\ln \left(\mathrm{f}_{\mathrm{r}}\right)$. The amount of $\mathrm{Hg}^{\mathrm{II}}$ remaining in

705 the reactor was used to calculate $\mathrm{f}_{\mathrm{r}}$ (see Methods). The $3 \mathrm{~h}$ time point for phototrophic cells in

706 replicates \#1 and 2 were omitted from the regression fitted to the data for $\operatorname{Hg}^{0}(\mathrm{~A}, \mathrm{~B})$ as this

707 suggested an alternative process was contributing to isotopic fractionation earlier on in the

708 experiment. No significant regressions were obtained for chemotrophic cells and as such no

709 models are presented.

711 Table S1: Total $\mathrm{Hg}$ concentrations and $\mathrm{Hg}$ isotope ratios for the reactant pool $\mathrm{Hg}^{\mathrm{II}}$ in

712 phototrophic and chemotrophic growth conditions experiments. Each line corresponds to an

713 individual sample and technical duplicates were taken for each time point. Std represents the

714 standard deviation from analytical replicates on the MC-ICP-MS. Abbreviations denote Metabo.

$715=$ Metabolism; Photo. $=$ Phototrophy; Chemo. $=$ Chemotrophy; Treat. $=$ Treatment; Hg conc. $=$

716 Hg concentration, rep = replicate; Avg = average; Std = Standard deviation; $\mathrm{ctl}=$ control, MED

$717=$ medium. $\delta^{202} \mathrm{Hg}$ values in bold denote those that deviate substantially from the composition of

718 the NIST 3133 standard in medium spiked controls.

720 Table S2: Total $\mathrm{Hg}$ concentrations and $\mathrm{Hg}$ isotope ratios for the $\mathrm{Hg}^{0}$ pool in phototrophic and

721 chemotrophic growth conditions experiments. Each line corresponds to the $\mathrm{Hg}$ present on two

722 gold traps used to sample each time point in parallel. Std represents the standard deviation from

723 analytical replicates on the MC-ICP-MS. Abbreviations denote the following: Metabo. = 
724 Metabolism; Photo. = Phototrophy; Chemo. = Chemotrophy; Treat. $=$ Treatment; Hg conc. $=\mathrm{Hg}$

725 concentration, rep = replicate; Avg = average; Std = Standard deviation

727 Table S3: Summary of regression models for mass dependent fractionation of ${ }^{202} \mathrm{Hg}^{\mathrm{II}}$ and ${ }^{202} \mathrm{Hg}^{0}$

728 in phototrophically and chemotrophically grown $H$. modesticaldum cultures. P-values for

729 regressions that displayed a significant $(\mathrm{p}<0.05)$ fit are shown in bold.

731 Table S4: Comparison of measured and calculated isotope fractionation values for the reactant

732 pool of $\mathrm{Hg}^{\mathrm{II}}$ using a mass balance approach. Measured values of $\mathrm{Hg}$ concentration and $\delta^{202} \mathrm{Hg}$ are

733 represented as an average of replicates from experiments presented in Tables S1 and S3.

734 Predicted values for media were obtained using the equations outlined for mass balance

735 calculations. Differences between the measured and predicted values that are substantially

736 greater than the analytical variability of measurements $(2 \mathrm{SD}=0.08)$ are shown in bold.

737 Abbreviations denote Photo. = phototrophic, Chemo. = chemotrophic, rep $=$ replicates, Avg. $=$ 738 average, Pred. $=$ predicted

740 Table S5: Comparison of enrichment factors and measures of variability used in this study and

741 the original cited work. Values in bold represent calculation ratios that differ between the

742 original article cited and the current study. Abbreviations: $\mathrm{SD}=$ standard deviation, $\mathrm{SE}=$

743 standard error, $\mathrm{p}=$ product, $\mathrm{r}=$ reactant, Ox. = oxygenic, Anox. $=$ anoxygenic, $\mathrm{PS}=$

744 photosynthesis. 